\title{
Endophyte fungus levels in perennial ryegrass and tall fescue varieties grown for seed in Oregon, USA - implications for responsible grass straw use as livestock feed
}

\author{
W.C. YOUNG III, M.E. MELLBYE, T.B. SILBERSTEIN, G.A. GINGRICH, \\ A.M. CRAIG and L.L. BLYTHE \\ Oregon State University, Corvallis, OR 97331 \\ william.c.young@oregonstate.edu
}

\begin{abstract}
Baling of perennial ryegrass (Lolium perenne) and tall fescue (Festuca arundinacea) straw residue following seed harvest has become a common practice in Oregon's grass seed industry. In 2005, almost 670000 tons [607 $000 \mathrm{Mg}$ (tonne)] of grass straw was exported to Japan and Korea for use as livestock feed. Most of the grass seed varieties grown today are turf-type, which in recent years have been developed with high levels of fungal endophyte infection. Currently, over $73 \%$ and $43 \%$ of perennial ryegrass and tall fescue varieties, respectively, are ranked as having a "High" (>61\% infected) infection level. Concern for the safe use of these grass straw residues had led to their routine analysis for toxin content before shipment to consuming markets. These chemical analyses provide assurances against deleterious effects to livestock fed Oregon grass straw.
\end{abstract}

Keywords: straw, endophyte-infected, perennial ryegrass, tall fescue

\section{Introduction}

The Oregon seed industry has followed the development of the association between endophyte-infected tall fescue and perennial ryegrass with considerable interest. Indeed, the dual nature of endophytes as anti-quality factors (resulting from their alkaloidrelated toxicity to livestock), and their additional association between insect resistance and persistence in turf grass have presented challenges to this industry as both endophyte-free and endophyte-infected varieties of both species are widely grown.

Oregon is widely recognised as a centre for the production of forage and turf grass seed crops. Annually, over 525000 acres (212 000 hectares) of mainly perennial ryegrass and tall fescue are now grown. Traditionally, grass straw residue following seed harvest was disposed of by open field burning. However, this practice declined during the 1990 s as the State legislatively mandated for a reduction in the amount of smoke produced. By

Figure 1 Endophyte fungus levels in seed of perennial ryegrass varieties (1980 - 2006).

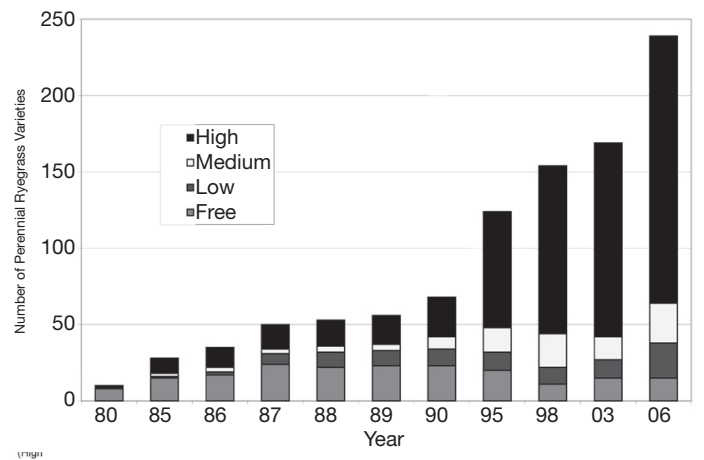

2005 , about $3 \%$ of all perennial ryegrass areas were managed with fire and $<1 \%$ of tall fescue fields. Thus, in the last decade, the volume of grass seed straw residue baled and used for livestock feed has more than doubled.

Over the last 25 years, much of the grass seed industry's focus has been on producing turf-type varieties. Increasingly, these varieties are infected with the endophytic fungi Neotyphodium lolii or $N$. coenophialum. These varieties are in demand by the landscape and golf industry due to the benefits the plant host derives from the symbiotic relationship with the endophyte. However, these endophytic fungi are known to produce the ergot alkaloids lolitrem B and ergovaline, which can have deleterious effects on livestock if consumed in excess. Thus, knowing the level of endophyte fungus infection in turf grass varieties is necessary as a first step in safe-guarding livestock being fed grass straw.

\section{Methods}

Survey data have been periodically collected for perennial ryegrass and tall fescue varieties grown for seed over the past 25 years. These data have been acquired from those companies listed as the contractor of each variety by the Oregon State University Seed Certification Service; no actual testing for determination of toxins was preformed. Using these results, levels of endophyte fungus infection of seed were categorised as High (61-100\%), Medium (31-60\%), Low (1-30\%) and Free (0\%) for different varieties and species over years. Bar graphs were drawn to emphasise the change that has occurred in varieties grown, and to reinforce the need for accurate sampling and assessment of toxin levels.

\section{Results}

Only $10 \%$ of perennial ryegrass varieties reported had a "High" level of infection in 1980; however, by 2006 varieties in this

Figure 2 Endophyte fungus levels (\%) in perennial ryegrass varieties (1980 - 2006).

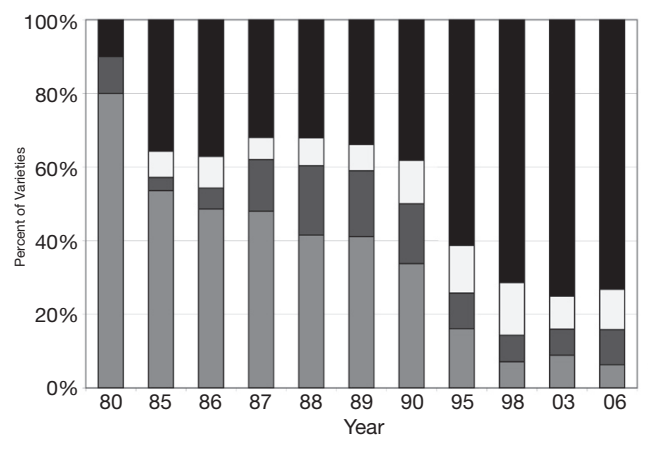


Figure 3 Endophyte fungus levels in seed of tall fescue varieties (1980 - 2006).

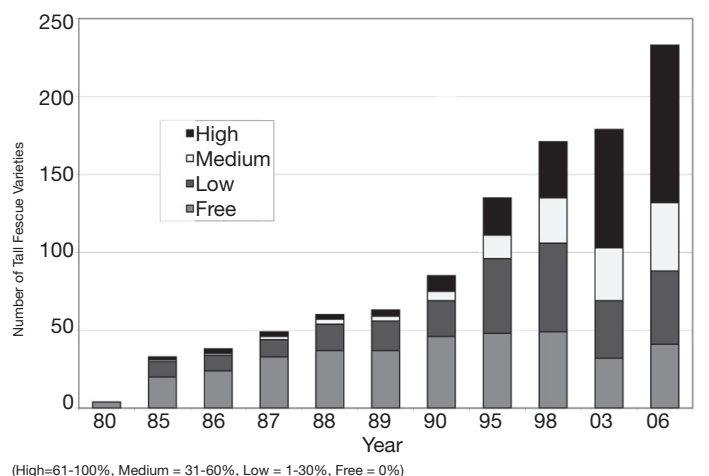

category had risen to over $73 \%$ (Figs. $1 \& 2$ ). Similarly, for tall fescue there were no endophyte-infected varieties in 1980, but by 2006 over $43 \%$ of all varieties grown were in the "High" category (Figs. $3 \& 4$ ). These data provide clear evidence of the increasing presence of endophytes in these two major seed crops grown in Oregon.

It is also apparent that there has been a large increase in the number of varieties grown for both species. In 1980, only 10 perennial ryegrass varieties were recorded and of these eight were endophyte-free. However, by 2006 there were 239 varieties of perennial ryegrass of which only 15 (6.3\%) were endophyte-free. Similarly, in 1980, only four tall fescue varieties were recorded and all were endophyte-free. Again, by 2006, 233 varieties of tall fescue were reported of which only $41(17.6 \%)$ were endophytefree. The increased use of endophytes in turf-type grasses in the mid-1980's resulted from reports of insect resistance to and better persistence (Funk et al. 1984).

Concomitant with the increased presence of endophytic fungi in turf grass varieties there has been an expansion in the export of grass straw to Pacific Rim countries - in particular, Japan and Korea. Last year (2005) almost 670000 tons [607 000 $\mathrm{Mg}$ (tonne)] of grass straw was exported to Japan (59\%) and Korea (39\%); perennial ryegrass straw was $49 \%$ of this tonnage and tall fescue was $44 \%$. To protect this valuable market, the Oregon State University College of Veterinary Medicine has refined laboratory procedures for measuring amounts of specific endophyte alkaloids in grass straw using high-performance liquid chromatography (Craig et al. 1994; Hovermale \& Craig 2001). This testing service is now used by Oregon straw exporters to insure that ergovaline and lolitrem B levels are below the thresholds known to produce clinical signs in livestock. In the last decade, the number of sample processed had more than tripled (L.L. Blythe, pers. comm.).

In 2006, the College of Agricultural Science's Endophyte Service Laboratory analysed 1566 grass straw samples (A.M. Craig, pers. comm.) of which 822 were tall fescue and 744 were perennial ryegrass. One hundred and sixty-six (20\%) of the tall fescue samples tested $>500 \mathrm{ppb}$ ergovaline, and 91 perennial ryegrass $(12 \%)$ samples tested $>2000 \mathrm{ppb}$ lolitrem $\mathrm{B}$. These alkaloids levels have been predetermined as thresholds for use of undiluted grass straw in livestock rations; thus, these lots of straw were not shipped for feed.

\section{Discussion}

Experiments and case studies conducted at the Oregon State University College of Veterinary Medicine and elsewhere have determined threshold levels of ergovaline and lolitrem B in the diet of cattle to be 400-750 ppb and $1800-2000$, respectively (Aldrich-Markham et al. 2003). It is important to emphasise that
Figure 4 Endophyte fungus levels (\%) in tall fescue varieties (1980 - 2006).

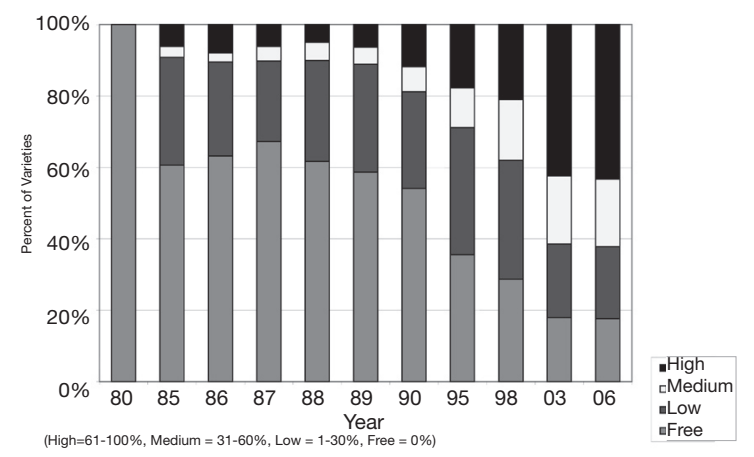

these thresholds refer to the level of toxin in the total diet, not in single feed components. Thus, forages with high levels of toxin may be fed safely when diluted with other feedstuffs. Threshold levels resulting in clinical disease are known to vary due to the role of environment and livestock stress. Therefore, avoidance of endophyte-infected tall fescue straw, especially in the winter when it can cause dry gangrene of the limbs, ears and tails, will prevent livestock losses. In addition, variation in ergovaline production among endophyte-infected tall fescue genotypes can occur between years (Welty et al. 1994).

The cost for each sample/assay is US\$40, which is recommended to be taken using commercial forage samplers. Bales are sampled by centering a core sampler in the end of the bale and drilling horizontally; 20 random cores (one per bale) are recommended for each "lot" of straw. Oregon straw exporters are now commonly testing 200-ton [181 Mg (tonne)] lots of grass seed straw as they are prepared for export. Oregon grass seed grower and straw handlers/exporters are confident that grass seed straw can be safely fed using this two-step approach to avoiding toxic alkaloid concentrations. First, know the endophyte infection level of the grass variety being baled, and if there is some question as to the source of the straw, have it analysed for lolitrem B and ergovaline alkaloids.

\section{REFERENCES}

Aldrich-Markham, S.M.; Pirelli, G.; Craig, A.M. 2003. Endophyte toxins in grass seed fields and straw effects on livestock. Oregon State University Extension Service. Ext. Comm. EM 8598.

Craig, A.M.; Bilich, D.; Hovermale, J.T.; Welty, R.E. 1994. Improved extraction and HPLC methods for ergovaline from plant material and rumen fluid. Journal of Veterinary Diagnostic Investigation 6(3): 348-352.

Funk, C.R.; Saha, D.C.; Johnson-Cicalese, J.M. 1984. Association of endophytic fungi with increased persistence and improved performance of perennial ryegrass and tall fescue in low maintenance turfs seeded in 1976. Rutgers Turfgrass Proceedings 15: 134-146.

Hovermale, J.T.; Craig, A.M. 2001. Correlation of ergovaline and lolitrem B levels in endophyte infected perennial ryegrass (Lolium perenne). Journal of Veterinary Diagnostic Investigation 13(4): 323-327.

Welty, R.E.; Craig, A.M.; Azevedo, M.D. 1994. Variability of ergovaline in seeds and straw and endophyte infection in seeds among endophyte-infected genotypes of tall fescue. Plant Diseases 78: 845-849. 